\title{
ANALISIS PENGARUH KOMPETENSI TERHADAP PERAN-PERAN BARU PROFESIONAL SUMBER DAYA MANUSIA
}

\author{
Dianawati Suryaningtyas \\ Email : dianawati_suryaningtyas@yahoo.com
}

\begin{abstract}
The fast changes and complexity of busines environment in global situation has forced many companies to make transformation in organization for gaining sustainable competitive advantage. Facing this new challenge, many of them have made human resource transformation. High standard quality of competencies of human resource professionals are needed to perform their roles excellently, in order to be succeeded in implementing human resource transformation. This survey research identifies and describes competencies of human resource professionals and the current execution of their roles. It also examines the significant influence of those competencies on roles of human resource professionals within human resource transformation. Respondents are Human Resource Manager or similar position in human resource or the person in charge in human resource. Convenience sampling is used to obtain samples in the communities of Human Resource Managers in Sidoarjo dan Pasuruan. Referring to complexity of the research framework and amount of samples, partial least square is used to analyse data. This research analyses the significant influence of $H R$ Competencies on HR Roles. The result shows that HR Competencies on HR Professional Competencies have the most significant influence on HR Roles on Operational Focus. In conclusion, the respondents' position is still on traditional human resource function and work more on day-to-day activities (operational). It reveals that human resource transformation is not done in their companies yet. Implication to repondents is that they need human resource consultant to help them implement human resource transformation because they are still lack of competencies and roles.
\end{abstract}

Key words : Human resource competencies, human resource roles, human resource transformation, human resource function, business environment change

Dianawati Suryaningtyas, adalah Dosen Fakultas Ekonomi Universitas Kanjuruhan Malang 


\section{PENDAHULUAN}

Perkembangan ekonomi ke arah globalisasi telah dimulai sejak akhir tahun 1980an. Sejalan dengan perkembangan ekonomi global, para ilmuwan terkemuka di dunia telah pula mengembangkan ilmu-ilmu manajemen termasuk diantaranya ilmu manajemen sumber daya manusia. Manajemen sumber daya manusia telah berevolusi lebih dari dua dekade yang lalu. Pergeseran paradigma terkait dengan ilmu yang mengelola aktifitas manusia dalam suatu organisasi yang semula adalah manajemen personalia, telah bergeser kepada manajemen sumber daya manusia. Pergeseran paradigma ini telah menghasilkan peran-peran profesional sumber daya manusia (SDM) yang semula hanya berperan sebagai tenaga administratif saja menjadi peran-peran yang lebih komprehensif dan strategis. Perubahan yang signifikan ini dikenal pula dengan sebutan transformasi sumber daya manusia.

Peran-peran baru profesional SDM yang telah banyak dikenal di seluruh dunia dan telah banyak pula diimplementasikan oleh perusahaan-perusahaan besar di Indonesia ini adalah merupakan konsep yang dihasilkan oleh tim riset dari Michigan University, Amerika Serikat, dengan ilmuwan yang bernama Dave Ulrich beserta timnya. Peran-peran baru profesional SDM tersebut adalah peran sebagai Mitra Strategis (Strategic Partner), Pemenang Pekerja (Employee Champion), Agen Perubahan (Change Agent), dan Ahli Administratif (Administrative Expert). Peran-peran baru tersebut harus dimiliki oleh para profesional SDM untuk melaksanakan transformasi SDM dalam organisasi. Dan para profesional SDM akan berhasil melaksanakan transformasi SDM jika mampu menjalankan keempat peran tersebut secara komprehensif. Untuk melaksanakan keempat peran tersebut, dibutuhkan kompetensi-kompetensi tertentu yang mendukung pencapaian transformasi SDM. Seperti yang disampaikan oleh Ulrich melalui pernyataannya: "People want to know what set of skills high-achieving $H R$ people need to perform even better," says Ulrich, co-director of the project along with Wayne Brockbank, also a professor of business at the University of Michigan (Sharpe, 2007). Oleh karena itu, tim dari Ulrich telah mempublikasikan Human Resource Competency Study (HRCS) Model 2007 yang merupakan hasil penelitian putaran kelima dan penyempurnaan dari keempat putaran sebelumnya. Hasil penelitian tersebut adalah terdiri dari 6 kompetensi, yaitu : Aktifis yang Terpercaya (Credible Activist), Kemampuan Memahami Bisnis (Business Ally), Perancang Strategis (Strategic Achitect), Pelaksana Operasional (Operational Executor), Pengelola SDM Potensial dan Perancang Organisasi (Talent Manager and Organization Designer), Pelaksana Perubahan dan Budaya (Culture and Change Steward).

Di Indonesia, konsep transformasi sumber daya manusia ini telah digunakan oleh Lembaga Manajemen Universitas Indonesia yang bekerja sama dengan majalah SWA sejak tahun 2006 dengan mengadakan "HR Excellence Awards Competition". Lebih dari 300 perusahaan dan instansi besar baik swasta maupun badan usaha milik negara yang telah mengikuti kompetisi tersebut. Dasar penilaian perusahaan yang sukses mengikuti kompetisi adalah keberhasilan melakukan transformasi sumber daya manusia dengan menggunakan konsep dari Ulrich tersebut (Soetjipto, 2008). Kompetisi tersebut dilaksanakan setiap tahun dan masih berjalan hingga sekarang (Website Lembaga Manajemen FE UI, 2013). 
Sejak dilaksanakannya kompetisi tersebut hingga sekarang, semakin banyak perusahaan maupun instansi yang telah melakukan transformasi SDM. Dengan demikian, telah banyak pula para pemilik perusahaan yang telah merubah paradigmanya dan merasa penting untuk melakukan transformasi SDM, jika menginginkan perusahaannya tetap eksis dan mampu bersaing di pasar global dengan persaingan yang semakin tajam dan cepat sekali berubah situasinya. Namun, apakah transformasi SDM ini telah banyak pula dilakukan oleh perusahaan-perusahaan yang ada di Sidoarjo dan Pasuruan? Apakah peran-peran para Manajer SDM telah berubah kepada peran-peran SDM yang lebih strategis? Apakah para Manajer SDM telah Untuk mengetahui hal tersebut, telah dilakukan penelitian terhadap para manajer SDM di kedua kota tersebut yang tergabung didalam komunitas yang dibentuk oleh kalangan mereka sendiri.

\section{TINJAUAN PUSTAKA}

\section{Kompetensi Sumber Daya Manusia}

Sejak dua dekade terakhir, pengembangan manajemen sumber daya manusia menitik-beratkan pada peran SDM dan kompetensi-kompetensinya. Menurut pendapat dari Clardy, bahwa, "the issue of human resource roles and competencies has been a theoretical and research focus for a number of years in the human resource development field. The primary reason for this is the obvious relation between human resource roles and competency and performance" (Clardy, 2008: Erasmus et al., 2010). Masalah peran-peran SDM dan kompetensikompetensinya telah menjadi fokus utama penelitian sejak beberapa tahun terakhir. Alasan utamanya adalah hubungan yang nyata antara peran-peran SDM dan kompetensi serta kinerja. Para peneliti menekankan pada dibutuhkannya kompetensi-kompetensi profesional SDM yang penting untuk melaksanakan peranperan baru tersebut, seperti pernyataan Schuler, "the requirements of $H R$ competencies that are important to execute the new HR Roles and to demonstrate capabilities of HR professionals in order to get credibility among them in the organization. That revolutionary change, increasing volatility, and the blurring of boundaries in the business world have resulted in an emphasis on the alignment of all functional activities of the organization toward the achievement of strategic objectives. One consequence of this trend is that many have called for a new strategic role for the HR function" (Schuler,1992; Lemmergaard, 2008; Suryaningtyas, 2011: 7).

Sejalan dengan perkembangan fungsi SDM yang menjadi strategis, para peneliti berusaha menemukan kompetensi-kompetensi yang tepat dan dibutuhkan untuk melaksanakan peran SDM strategis tersebut demi keberhasilan suatu organisasi. Dalam suatu penelitian di tahun 2004, the American Society for Training and Development (ASTD) mendefinisikan peran-peran sebagai, "groupings of targeted competencies". Sedangkan kompetensi didefinisikan sebagai, "clusters of skills, knowledge, abilities and behavior for job success". Kompetensi adalah sekelompok ketrampilan, pengetahuan, kemampuan dan perilaku untuk mencapai kesuksesan suatu pekerjaan. Shermon (2010) mendefinisikan kompetensi sebagai "an underlying characteristic of a person, which enables him to deliver superior performance in a given job, role of situation" 
(Shermon D., 2010: 11). Kompentensi memiliki definisi tersendiri, namun jika digunakan didalam konteks sistem SDM, maka kompetensi memiliki pengertian dan konteks yang berbeda. Menurut Rothwell \& Wellins (2004; Ramlall, 2006), suatu model kompetensi dapat menjadi kerangka kerja yang integratif bagi keseluruhan sistem organisasi. Hal ini dapat membantu keselarasan sistem SDM secara vertikal dengan tujuan strategis organisasi, atau secara horisontal dengan fungsi-fungsi SDM, untuk memastikan keharmonisan dan konsistensi didalam menghadapi banyak aktifitas SDM yang akan memberikan dampak kepada kinerja SDM.

Tuntutan adanya kompetensi SDM yang dibutuhkan untuk melaksanakan peran-peran strategis SDM haruslah kompetensi yang dapat memenuhi adanya tuntutan perubahan didalam dunia bisnis yang semakin mengglobal, mampu memenuhi kebutuhan pelanggan dan pemegang saham, yang pada intinya mampu memiliki keunggulan kompetitif bagi perusahaan serta meningkatkan kinerja yang berujung pada peningkatan profibilitas. Kompetensi-kompetensi yang dimiliki para profesional SDM haruslah mampu memberikan nilai (deliver value) kepada pencapaian organisasi secara berkelanjutan didalam proses transformasi SDM. Adapun kompetensi-kompetensi SDM yang tepat dan dibutuhkan bagi pencapaian tersebut adalah yang telah dihasilkan oleh tim Ulrich dalam model Kompetensi sebagai berikut :

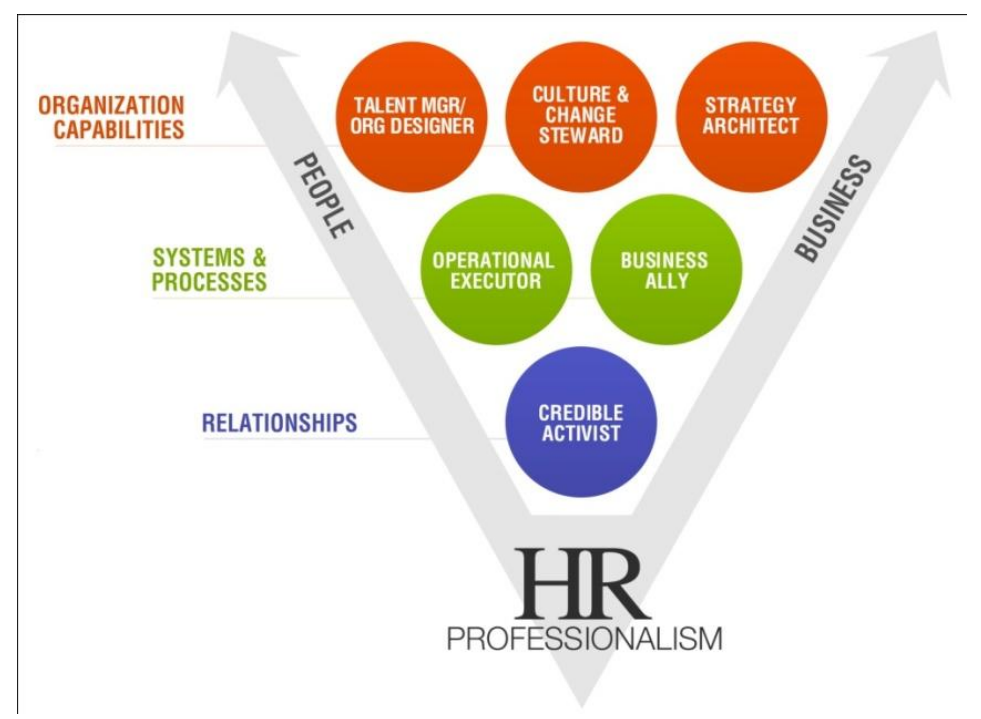

Gambar 1. Human Resource Competency Study (HRCS) 2007

Sumber : Ulrich \& RBL Research Team, 2010.

Dalam Gambar 1, Ulrich \& RBL Research Team menunjukkan bahwa profesional SDM yang sukses harus mampu mengelola baik orang maupun bisnis, yang berorientasi pada aktifitas saat ini dan yang akan datang. Profesional SDM juga harus menyadari kebutuhan orang-orang didalam organisasi. Mereka juga 
harus bertanggungjawab terhadap kebutuhan bisnis organisasi. Keenam kompetensi yang ada didalam HRCS 2007 adalah sebagai berikut :

1) Credible Activist

Credible Activist adalah kompetensi yang harus dimiliki profesional SDM untuk menciptakan pencapaian bisnis (business outcomes) bagi keunggulan kompetitif organisasi secara berkelanjutan. Profesional SDM harus dapat dipercaya, dihargai, mampu memberikan beberapa pandangan, serta mampu bertindak dalam menyelaraskan hubungan antara dimensi orang dan bisnis.

\section{2) Business Ally}

Business Ally adalah kompetensi yang harus dimiliki profresional SDM yang dapat memberikan kontribusi bagi kesuksesan bisnis dengan memahami konteks sosial atau lingkungan eksternal yang akan berpengaruh terhadap operasional bisnis. Profesional SDM juga harus mengetahui proses bisnis organisasi dan fungsi-fungsi tiap departemen dan bagaimana cara mereka bekerja bersama-sama, mengenali kebutuhan pelanggan dan bagaimana organisasi merespons kebutuhan pelanggan.

\section{3) Strategy Architect}

Strategy Architect adalah kompetensi yang harus dimiliki oleh profesional SDM yang mampu memandang (vision) bagaimana organisasi dapat berperan dan memenangkan persaingan dipasar bebas, saat ini dan dimasa yang akan datang. Profesional SDM memainkan peran aktif didalam menetapkan strategi organisasi untuk pencapaian visi tersebut. Profesional SDM juga harus mampu membuat strategi organisasi menjadi implementasi SDM berupa praktik-praktik SDM yang berujung pada pencapaian kapabilitas organisasi. Mereka harus dapat memastikan bahwa perilaku para pimpinan didalam organisasi harus selaras dengan strategi organisasi. Mereka membantu mengartikulasikan bagaimana strategi menjembatani karyawan didalam dan pelanggan diluar organisasi. Profesional SDM ini mengelola proses tentang siapa yang akan terlibat didalam pembentukan strategi.

\section{4) Operational Executor}

Operational Executor adalah kompetensi yang harus dimiliki oleh profesional SDM didalam melaksanakan aspek-aspek operasional didalam mengelola orang dan organisasi. Kompetensi pelaksana operasional ini merupakan kredibilitas profesional SDM didalam pelaksanaan operasional yang sempurna dan didasarkan pada aplikasi kebijakan yang konsisten. Profesional SDM secara rutin akan menerima umpan-balik dari karyawan terkait pelaksanaan operasional yang akurat, cepat, responsif.

\section{5) Talent Manager / Organization Designer}

Talent Manager / Organization Designer adalah kompetensi yang harus dimiliki profesional SDM untuk memastikan bahwa pengelolalaan SDM potensial (talent management) dan kapabilitas organisasi selaras dengan strategi, terintegrasi satu sama lain, bekerja secara efektif dan efisien. Talent management fokus pada kompetensi yang dibutuhkan SDM (karyawan) memasuki, berkembang, dan keluar dari organisasi. Organizational designer fokus pada bagaimana organisasi membangun kapabilitas (misalnya : kolaborasi, inovasi) kedalam struktur, proses, dan kebijakan yang membentuk 
cara mereka bekerja. Keduanya tidak dapat berjalan sendiri-sendiri, harus bersama-sama.

\section{6) Culture and Change Steward.}

Culture and Change Steward adalah kompetensi yang harus dimiliki profesional SDM dalam menghargai, mengartikulasikan, dan membantu membentuk budaya organisasi. Budaya adalah pola aktifitas yang dimulai dari kejelasan harapan-harapan lingkungan eksternal dan kemudian menerjemahkan harapan-harapan tersebut kedalam perilaku internal karyawan dan organisasi. profesional SDM menghargai budaya lama dan membantu membentuk budaya baru. Mereka melatih para manajer bagaimana tindakan mereka merefleksikan dan mengarahkan budaya, menjadikan budaya standart kedalam praktik-praktik dan proses SDM, serta membuat budaya menjadi nyata buat karyawan. Profesional SDM yang sukses memfasilitasi perubahan dengan membantu mengembangkan budaya organisasi yang baik dan mengembangkan disiplin sehingga perubahan benar-benar dapat dilaksanakan di keseluruhan organisasi.

\section{Peran-peran Baru Profesional SDM}

Peran-peran baru profesional SDM adalah hasil dari proses evolusi teori manajemen sumber daya manusia dari peran administratif kepada peran-peran baru yang lebih strategis dan komprehensif, terintegrasi dan selaras dengan tujuan organisasi, serta memberikan nilai (deliver value) kepada keunggulan kompetitif organisasi. Gambar 2 adalah konsep peran-peran baru dari profesional SDM yang dikemukakan oleh Ulrich dan telah digunakan oleh banyak perusahaan di dunia.

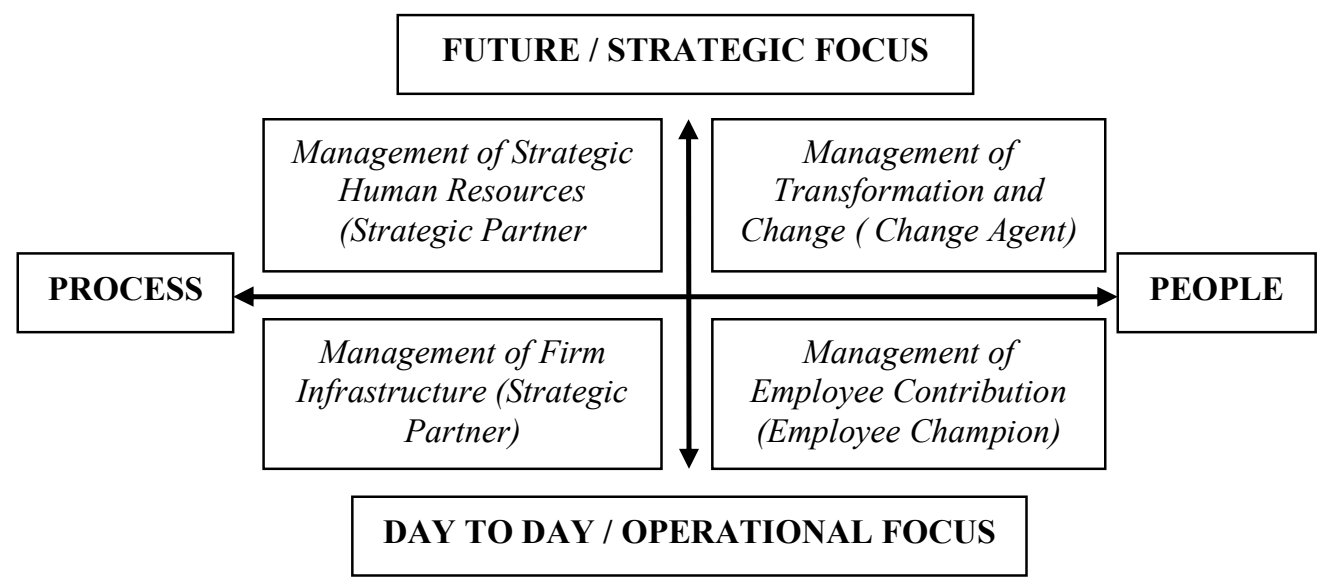

\section{Gambar 2. Peran-peran Baru SDM dalam menciptakan Keunggulan Organisasi}

Sumber: Ulrich, Dave, "Human Resource Champions, The Next Agenda For Adding Value And Delivering Results", dikutip dari Wang, Y.D and Niu, H.J.: 2010.

Kedua anak panah pada Gambar 2 menunjukkan profesionalitas SDM didalam aktifitas kerja dan fokusnya. Pada bagian sumbu sebelah kanan, 
profesional SDM memfokuskan pada jangka panjang atau strategis dan berorientasi pada orang. Sedangkan bagian sumbu lainnya memfokuskan pada aktifitas jangka pendek atau operasional dan berorientasi pada proses. Kempat peran baru profesional SDM yang terdapat dalam Gambar 2 adalah :

1) Strategic Partner

Peran profesional SDM sebagai mitra strategis organisasi yang berfokus pada jangka panjang dan strategis serta berorientasi pada proses ini merupakan peran kunci didalam merancang organisasi mencapai tujuannya. Sebagai mitra strategis organisasi, profesional SDM harus mampu melaksanakan strategi organisasi melalui fungsi-fungsi SDM dan bekerja sama dengan manajer senior dan manajer lini dalam memfokuskan bagaimana memastikan seluruh kebutuhan organisasi. Profesional SDM harus mampu memantaskan strategi SDM kedalam tujuan organisasi.

2) Change Agent

Peran profesional SDM sebagai agent perubahan yang didasarkan pada fokus strategis dan berorientasi pada orang, bertujuan dalam melaksanakan transformasi SDM serta perubahan yang harus dilakukan oleh organisasi. Peran ini memfokuskan pada memastikan bahwa organisasi memiliki kapasitas menangani perubahan. Agen perubahan bertanggungjawab terhadap perubahan budaya didalam proses transformasi organisasi. Peran ini menciptakan nilai dengan memastikan seluruh organisasi dapat berubah sesuai dengan kondisi dengan membangun kapabilitas berubah menjadi kompetensi inti (core competencies)

3) Employee Champion

Peran profesional SDM yang memfokuskan pada jangka pendek atau operasional dan berorientasi pada orang, menekankan pada kebutuhan karyawan dengan tujuan meningkatkan komitmen dan kapabilitas.

4) Administrative Expert

Peran ahli administratif ini masih melekat sebagai peran tradisional profesional SDM yaitu mengelola kebutuhan administrasi karyawan. Dengan penggunaan tehnologi terbaru, peran administratif ini menjadi semakin efisien dan efektif.

\section{Memahami Transformasi Sumber Daya Manusia}

Menurut Ulrich dan timnya, transformasi sumber daya manusia adalah, " $a$ true HR transformation is an integrated, aligned, innovative, and business focus approach to redefining how HR work is done within an organization so that it helps the organization deliver on promises made to customers, investors, and stakeholders (Ulrich et al., 2009: 8-9). Transformasi sumber daya manusia adalah perubahan praktek dan fungsi SDM kearah yang lebih strategis, terintegrasi, selaras, inovatif, dan fokus pada bisnis sehingga dapat membantu organisasi didalam memenuhi kebutuhan pelanggan, investor, dan para pemegang saham. Ulrich dan timnya juga menyatakan bahwa profesional SDM senior bertanggungjawab didalam memastikan bahwa praktek-praktek dan fungsi-fungsi SDM selaras dan mendorong keberhasilan bisnis. Peran strategis ini dapat dilaksanakan dengan keikutsertaannya didalam merumuskan strategi organisasi, seperti yang dinyatakan, "To fullfill their HR leadership role, they need to be active participants in the 
prosess of setting business strategy. They can then set direction for transformation, design a process that focuses on HR results, engage people in the process, execute to ensure transformation happens, and make sure it endures. HR professionals should also be aware of the principles of HR transformation" (Ulrich et al., 2009: 4).

Didalam transformasi SDM, kesuksesan implementasinya didalam organisasi ada pada para manajer lini. Mereka adalah pelaksana dari semua strategi dan kebijakan yang dibuat oleh profesional SDM, seperti yang dinyatakan oleh Ulrich dan timnya, "line managers who believe that issues like talent, organizational capability development, strategy execution, and leadership are the keys to their business success. They increasingly look to HR for thought leadership, insightful recommendations, and practical processes for these issues" (Ulrich et al., 2009: 4). Transformasi SDM adalah merupakan transformasi fungsifungsi SDM, praktek-praktek SDM dan juga tranformasi kompetensi dan peranperan profesional SDM.

Dengan memahami pengertian tentang transformasi SDM, maka fungsi dan praktek SDM yang sebelumnya adalah fokus pada fungsi dan praktek administratif dan operasional saja menjadi fungsi dan praktek SDM yang tradisional. Dengan berkembangnya teori manajemen sumber daya manusia, fungsi dan praktek SDM telah berubah. Tanggungjawab transformasi sumber daya manusia ada pada profesional SDM senior, yang berada pada posisi dan level strategis. Profesional SDM pada level menengah bekerja sama dengan para manajer lini didalam mengimplementasikan transfomasi SDM. Pada level operasional, fungsi dan praktek SDM dilaksanakan oleh karyawan SDM dan dioutsourcing- kan atau menggunakan sistem tehnologi SDM yang terintegrasi yang dikenal dengan HRIS (Human Resource Information System). Pemahaman tentang transformasi SDM ini dapat diilustrasikan seperti pada Gambar 3.

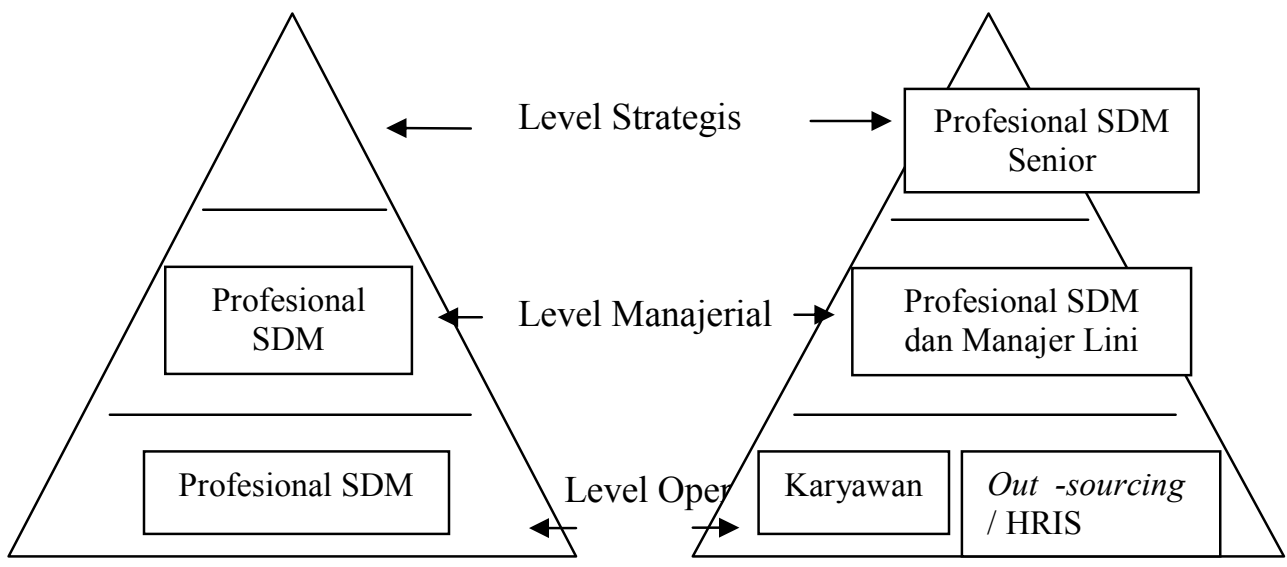

Fungsi SDM Tradisional $\underset{\text { Transformasi }}{\longrightarrow}$ Fungsi SDM yang Baru

Gambar 3. Transformasi Sumber Daya Manusia

Sumber: Suryaningtyas, 2011: 23 
Keberhasilan transformasi SDM terletak pada kompetensi profesional SDM senior yang bertanggungjawab terhadap pelaksanaan perubahan didalam organisasi. Kompetensi-kompetensi yang dibutuhkan dan dimiliki oleh profesional SDM senior harus memiliki standart kualifikasi yang tinggi dan tepat. Kompetensi-kompetensi yang dibutuhkan adalah kompetensi-kompetensi seperti yang telah disebutkan oleh Ulrich dan timnya setelah melalui serangkaian penelitian. Jika profesional SDM yang ada saat ini tidak memiliki standart kualifikasi kompetensi tersebut, maka profesional harus pula melakukan transformasi terhadap diri dan kompetensinya. Jika hal tersebut sulit dilaksanakan, maka organisasi harus mendapatkan profesional SDM senior dari luar organisasi.

\section{Hubungan Antara Kompetensi SDM dan Peran-peran Baru Profesional SDM}

Berubahnya peran profesional SDM kepada peran-peran baru yang lebih strategis, tentunya dibutuhkan kompetensi-kompetensi SDM yang memiliki kualifikasi tinggi untuk dapat melaksanakan peran-peran tersebut didalam proses transformasi SDM dan dapat memberikan nilai tambah kepada organisasi. Hubungan kompetensi yang dibutuhkan didalam menjalankan peran-peran baru profesional SDM senior, seperti yang dinyatakan oleh Meija, "HR needs to execute an active and guiding role in enabling a company to choose its people well, invest them with the proper responsibilities, support their growth and respect their needs in order to achieve an organization's strategic business objectives. This vital role requires competence in HR leaders that will create and sustain a flexible and adaptive workforce (Mejia, 2001: 18).

Didalam menjalankan perannya sebagai mitra strategis organisasi, profesional SDM senior harus memahami bisnis organisasinya dan serta mengetahui posisi organisasi tersebut di pasar, agar dapat mengarahkan strategi organisasi kepada keunggulan bersaing di pasar bebas. Hal ini sesuai dengan pernyataan dari Lawler III and Mohrman, "to become a successful strategic partner, the HR manager must have competencies that have to do with the business issues involved in strategy and strategy development, and ability to contribute to organizational design and change management" (Lawler III and Mohrman, 2003: Inyang, 2010). Hubungan kompetensi dengan peran-peran baru profesional SDM dinayatakan pula oleh Lipiec, "With the changing roles of HR professionals to become more strategically, it is expected that HR professionals perform those new roles with new competencies. As trends have emerged, Human Resource Management profesionals have been expected to occupy new roles, and some have suggested that the former functional Human Resource Management role has been supplanted by a more strategic role which requires new competencies" (Lipiec, 2001; Crouse et al., 2011).

Hubungan antara kompetensi yang terintegrasi dengan peran-peran baru profesional SDM sangat dibutuhkan bagi pengembangan dan aktifitas SDM, seperti pernyataan Ulrich dan timnya, "Companies focus their HR professionals development on HR competencies, which we believe integrate the roles and activities" (Ulrich et al., 2009: 102). Profesional SDM senior sebagai mitra bisnis harus bekerja sama dengan manajemen puncak dalam pencapaian strategi yang telah dirumuskan dan memahami bisnis secara komprehensif dalam mendesain organisasi yang memiliki kapabilitas. Hal ini dikemukakan oleh Mondy, bahwa 
"Human Resource executive must work with top management in achieving concrete plans and results if HR is to become a strategic partner. They must understand the operational side of the business and comprehend the complex organizational design, and they must be able to determine the strategic capabilities of the company's workforce, both today and in the future" (Mondy, 2010: 14).

Berdasarkan pemahaman terhadap beberapa pernyataan para ilmuwan tersebut, maka dapat diketahui bahwa untuk mengimplementasikan peran strategisnya, profesional SDM diharapkan dapat mentransformasikan kompetensinya dengan kompetensi-kompetensi kunci yang baru yang akan menempatkan mereka pada posisi dan level strategis di dalam organisasi sehingga mereka dapat bekerjasama dengan manajemen puncak didalam memberikan kontribusi kepada tujuan strategis organisasi. profesional SDM diharapkan mampu berkontribusi didalam merumuskan strategi organisasi maupun strategi bisnis. Profesional SDM senior diharapkan mampu menerjemahkan strategi organisasi kedalam rencana-rencana strategis dan pelaksanaannya yang berujung pada kapabilitas organisasi.

Hubungan antara kompetensi SDM dengan peran-peran baru profesional SDM dapat digambarkan secara konseptual seperti pada Gambar 4. Pada sisi sebelah kiri, kompetensi SDM direfleksikan kedalam dua dimensi yaitu kompetensi SDM yang strategis dan berorientasi pada proses (Business Related Competencies), dan kompetensi SDM yang "day to day" dan berorientasi pada orang (HR Professional Competencies). Sedangkan pada sisi sebelah kanan Gambar 4, peran-peran baru SDM (HR Roles) terdiri dari dua dimensi yaitu yang direfleksikan pada fokus strategis dan berorientasi pada masa yang akan datang serta fokus operasional dan berorientasi pada masa kini. Model konseptual pada Gambar 4 merupakan modifikasi dari dari model konseptual yang dibuat oleh Long dan Ismail (2008), dimana pada sisi kiri model digunakan kompetensi-kompetensi hasil penelitian Ulrich dan timnya pada putaran terakhir (HRCS 2007).

\begin{tabular}{|c|c|}
\hline $\begin{aligned} & \text { Business Related Competencies: } \\
& \text { 1) } \text { Business Ally } \\
& \text { 2) } \text { Strategy Architect }\end{aligned}$ & $\begin{array}{l}\quad \text { HR Roles } \\
\text { Strategic Focus } \\
\text { a) Strategic Partner } \\
\text { b) Change Agent }\end{array}$ \\
\hline $\begin{aligned} & \text { HR Professional Competencies: } \\
& \text { 3) } \text { Credible Activist } \\
& \text { 4) } \text { Operational Executor } \\
& \text { 5) } \text { Talent Manager \& Organization } \\
& \text { Designer } \\
& \text { 6) } \text { Culture \& Change Steward }\end{aligned}$ & $\begin{aligned} & \text { Operational Focus } \\
& \text { c) } \text { Employee } \\
& \text { Champion } \\
& \text { d) } \text { Administrative } \\
& \text { Expert }\end{aligned}$ \\
\hline
\end{tabular}

\section{Gambar 4. Model Konseptual}

Sumber : Modifikasi dari: Long, Choi S. \& Wan, K.W. Ismail, 2008, Suryaningtyas, 2011: 41 


\section{Kerangka Kerja Penelitian}

Hal yang mendasari dibuatnya kerangka kerja penelitian adalah pengembangan teori SDM yang merupakan hasil eksplorasi para ilmuwan dan peneliti selama dua dekade terakhir. Konsep transformasi SDM menurut Ulrich dan timnya, menekankan pada sinergi yang sangat kompleks antara kompetensikompetensi SDM (dalam perspektif proses dan orang) dengan peran-peran baru profesional SDM (dimensi strategis dan operasional). Peran-peran baru profesional SDM dapat dilaksanakan secara komprehensif dan terintegrasi didalam pencapaian strategi organisasi , jika kompetensi-kompetensi yang dibutuhkan tersebut dimiliki oleh profesional SDM senior.

Penelitian ini dilakukan untuk menguji adanya hubungan atau pengaruh yang signifikan antara kompetensi-kompetensi SDM dengan peran-peran baru profesional SDM, baik secara parsial maupun secara keseluruhan. Secara parsial dilakukan pengujian apakah masing-masing dimensi kompetensi SDM yaitu Business Related Competencies dan HR Professional Competencies memiliki hubungan yang signifikan dengan HR Roles pada dimensi Strategic Focus dan Operational Focus. Penelitian ini dilakukan untuk mengetahui adanya hubungan yang paling signifikan antara kompetensi-kompetensi SDM dengan peran-peran profesional SDM.

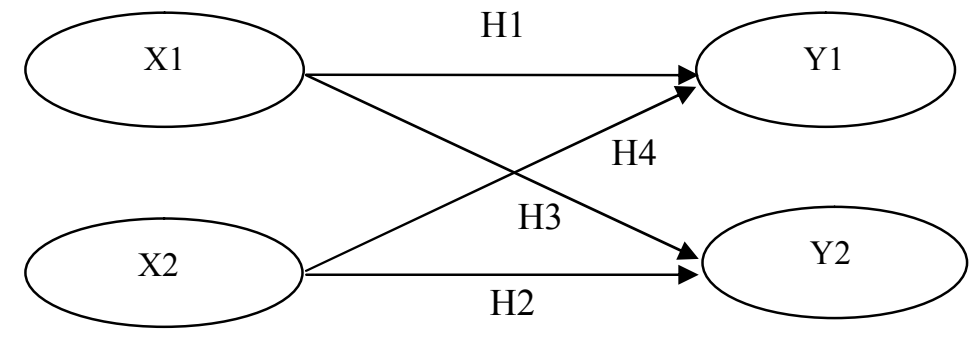

Gambar 5. Kerangka Kerja Penelitian

Catatan :

$\mathrm{X} 1=$ Kompetensi Terkait Bisnis (Business Related Competencies)

$\mathrm{X} 2=$ Kompetensi Profesional SDM (HR Professional Competencies)

$\mathrm{Y} 1=$ Peran Profesional SDM fokus pada peran strategis (HR Roles on Strategic Focus)

$\mathrm{Y} 2=$ Peran Profesional SDM fokus pada peran oeprasional (HR Roles on Operational Focus)

Hipotesis yang digunakan didalam penelitian ini adalah hipotesis nol (H0) dimana dinyatakan tidak terjadi adanya pengaruh atau perbedaan jika $\mathrm{H} 0$ diterima. Hipotesis alternatif (Hi) digunakan dan dinyatakan diterima jika hasil pengujian membuktikan adanya perubahan atau pengaruh. Pengujian statistik parametris digunakan untuk menguji hipotesis. Dalam penelitian ini, hipotesis dibuat berdasarkan kerangka kerja penelitian dan dirumuskan berdasarkan hubungan dari masing-masing dimensi dari kompetensi-kompetensi SDM dan peran-peran baru profesional SDM. Hipotesis yang digunakan dalam penelitian ini adalah : 
H1: Kompetensi Terkait Bisnis (Business Related Competencies) diharapkan memiliki pengaruh yang signifikan dengan Peran Profesional SDM fokus pada Peran Strategis (HR Roles on Strategic Focus)

H2: Kompetensi Profesional (SDM HR Professional Competencies) diharapkan memiliki pengaruh yang signifikan dengan Peran Profesional SDM fokus pada Peran Operasional (HR Roles on Operational Focus)

H3: Kompetensi Terkait Bisnis (Business Related Competencies) diharapkan memiliki pengaruh yang signifikan dengan Peran Profesional SDM fokus pada Operasional (HR Roles on Operational Focus)

H4: Kompetensi Profesional SDM (HR Professional Competencies) diharapkan memiliki pengaruh yang signifikan dengan Peran Profesional SDM fokus pada Peran Strategis (HR Roles on Strategic Focus)

\section{METODE}

\section{Populasi dan Sampling}

Penelitian ini dilaksanakan dengan menggunakan metode survey, yaitu tehik mengumpulkan data primer dengan menggunakan instrumen penelitian berupa kuesioner (questionnaires). Data yang terkumpul diseleksi berdasarkan kelengkapan data, kemudian dilakukan analisis data dan diinterpretasikan sehingga dihasilkan informasi yang spesifik dari responden melalui metode tersebut. Responden adalah para Manajer SDM yang bekerja di perusahaan-perusahaan manufaktur yang tergabung didalam kelompok komunitas atau perkumpulan Manajer SDM. Lokasi penelitian berada di Sidoarjo dan Pasuruan dan dilakukan pada tahun 2011. Unit analisis dibatasi pada responden yang bekerja sebagai Manager SDM Senior dan Manager SDM atau orang-orang yang memiliki posisi sejenis yang menangani SDM dan memiliki wewenang untuk menjawab semua pertanyaan yang ada di kuesioner (misalnya: Kepala Bagian Personalia, dan sejenisnya).

Penelitian ini menggunakan tehnik sampling Non-Probabilitas. Menurut Umar, dengan menggunakan tehnik ini, tidak seluruh elemen populasi memiliki kesempatan yang sama untuk menjadi sample karena bagian dari elemen-elemen tersebut yang secara intensional tidak termasuk kedalam seleksi yang mewakili populasi (Umar; 1997: 57). Tehnik ini sering digunakan oleh banyak peneliti untuk mendapatkan sample berdasarkan pertimbangan-pertimbangan tertentu. Sementara Malhotra menyebutkan bahwa, "commonly used non-probability sampling technique include convenience sampling, judgmental sampling, quota sampling, and snowball sampling (Malhotra, 2009: 375). Penelitian ini menggunakan Convenience sampling atau disebut juga Accidental sampling, yaitu suatu tipe nonprobability sampling yang melibatkan sample yang ditarik dari bagian populasi yang dapat dijangkau. Sehingga sample terpilih dari populasi karena sudah tersedia dan nyaman (convenient). Contoh dari convenience sampling adalah kelompok 
gereja, para anggota dari suatu organisasi. Didalam penelitian ini, responden adalah para anggota tiga Asosiasi Manajer SDM yang berada di Sidoarjo dan Pasuruan yang melakukan kegiatan pertemuan rutin setiap bulannya pada tanggal tertentu. Convenience sampling digunakan didalam penelitian ini didasarkan pertimbangan pada cara yang lebih mudah untuk mendapatkan responden, menyebarkan kuesioner dan mengumpulkannya kembali pada waktu yang sama. Karena adanya masalah-masalah tehnis internal dari ketiga asosiasi tersebut saat dilaksanakannya penelitian ini, maka responden yang diperoleh hanya berjumlah 46 responden.

\section{Variabel-variabel Penelitian}

Variabel adalah beberapa karakteristik suatu kelompok individu yang dapat mengambil nilai yang berbeda. Variabel yang dianalisis didalam penelitian ini adalah variabel independen dan variabel dependen. Variabel dependen didalam penelitian ini adalah variabel Y, yaitu variabel Peran-peran Baru Profesional SDM (HR Roles). Sedangkan variabel independen adalah variabel $\mathrm{X}$ yang terdiri dari Kompetensi-kompetensi SDM (HR Competencies). Identifikasi dari masingmasing variabel adalah sebagai berikut :

1. Variable independen, yatitu Kompetensi-kompetensi SDM (HR Competencies) yang merupakan variabel $\mathrm{X}$ yang merupakan :

a. Business Related Competency (X1), yang terdiri dari:
1) Business Ally (X1.1)
2) Strategy Architect (X1.2)

b. HR Professional Competencies (X2), yang terdiri dari:

1) Credible Activist (X2.1)

2) Operational Executor (X2.2)

3) Talent Manager \& Organization Designer (X2.3)

4) Culture and Change Steward (X2.4)

2. Variabel dependen yaitu Peran-peran Baru Profesional SDM (HR Roles) yang merupakan variabel $\mathrm{Y}$ yang merupakan :

a. HR Roles on Strategic Focus (Y1), yang terdiri dari:

1) Strategic Partner (Y1.1)

2) Change Agent (Y1.2)

b. HR Roles on Operational Focus (Y2), yang terdiri dari :

1) Employee Champion (Y2.1)

2) Administration Expert (Y2.2)

\section{Tehnik Analisis Data}

Berdasarkan rumusan hipotesis, maka tehnik analisis data yang digunakan seharusnya adalah SEM. Dengan adanya kuesioner yang dikembalikan oleh responden dan setelah diseleksi kelengkapan datanya hanya berjumlah 46, maka tehnik analisis data yang digunakan adalah Partial Least Square (PLS).

\section{PEMBAHASAN}

Didalam model Partial Least Square (PLS), hubungan setiap variabel diasumsikan linear. Metode yang digunakan untuk mengetes linearitas adalah 
Curve Fit. Jika Signifikan skor F tiap variabel kurang dari 0.05, maka hubungan variabel adalah linear. Hasilnya menunjukkan bahwa Significant $F=0.0000$ kurang dari 0.05, berarti hubungan model 1 yaitu Business Related Competencies dan HR Roles on Strategic Focus adalah linear. Demikian selanjutnya dilakukan pengetesan dengan metode yang sama terhadap model 2, 3, dan 4. Hasilnya menunjukkan bahwa keseluruhan model memiliki hubungan yang linear terhadap masing-masing variabel.

Outer Model (Measurement Model)

Didalam pengukuran model PLS, terdapat dua pengukuran inti yang paling menentukan yaitu Outer model dan Inner model. Langkah-langkah didalam mengevaluasi outer model adalah sebagai berikut :

\section{Convergent Validity}

Convergent Validity adalah suatu pengukuran untuk outer model dengan indikator-indikator reflektif yang dievaluasi berdasarkan korelasi antara item score / component score dengan construct score. Faktor loading yang direkomendasikan lebih dari 0.50 . Pengukuran individual reflektif adalah tinggi jika berkorelasi dengan konstruk yang diukur dengan skor lebih dari 0.50 (Chin, 1998: Ghozali, 2008: 24). Jika skor kurang dari 0.50, maka indikator ini harus dibuang dan tidak dimasukkan kedalam analisis. Hasil output PLS disajikan dalam Tabel 1 yang menunjukkan bahwa seluruh skor convergent validity lebih tinggi dari critical score 0.50 , yang berarti seluruh indikator didalam konstruk adalah valid.

Tabel 1. Outer Loading of Convergent Validity

\begin{tabular}{|c|c|c|c|c|c|c|}
\hline Items & $\begin{array}{c}\text { Business Related } \\
\text { Competencies }\end{array}$ & $\begin{array}{c}\text { HR } \\
\text { Professional } \\
\text { Competencies }\end{array}$ & $\begin{array}{c}\text { Operational } \\
\text { Focus }\end{array}$ & $\begin{array}{c}\text { Strategic } \\
\text { Focus }\end{array}$ & $\begin{array}{c}\text { Critical } \\
\text { Score }\end{array}$ & Mark \\
\hline X1.1 & 0.941436 & --- & --- & --- & 0.50 & Valid \\
\hline X1.2 & 0.941332 & --- & --- & --- & 0.50 & Valid \\
\hline X2.1 & --- & 0.909258 & --- & --- & 0.50 & Valid \\
\hline X2.2 & --- & 0.799565 & --- & --- & 0.50 & Valid \\
\hline X2.3 & --- & 0.897776 & --- & --- & 0.50 & Valid \\
\hline X2.4 & --- & 0.854272 & --- & --- & 0.50 & Valid \\
\hline Y1.1 & --- & --- & --- & 0.910772 & 0.50 & Valid \\
\hline Y1.2 & --- & --- & --- & 0.912337 & 0.50 & Valid \\
\hline Y2.1 & --- & --- & 0.936147 & --- & 0.50 & Valid \\
\hline Y2.2 & --- & --- & 0.953381 & --- & 0.50 & Valid \\
\hline
\end{tabular}

Sumber : Data primer diolah, Suryaningtyas, 2011: 91

\section{Discriminant Validity}

Jika korelasi konstruk dengan item pengukuran adalah lebih daripada pengukuran konstruk lainnya, maka hal ini menunjukkan bahwa konstruk laten memprediksikan ukuran blok mereka lebih baik daripada blok lainnya (Ghozali, 2008: 25). Hasil output PLS disajikan dalam Tabel 2, yang menunjukkan bahwa 
korelasi konstruk Busines Related Competencies (X1.1 dan X1.2) dengan indikatornya lebih tinggi dibandingkan dengan indikator korelasi Business Related Competencies dengan konstruk lainnya (HR Professional Competencies, Operational Focus, Strategic Focus). Hasil ini berlaku juga pada HR Professional Competencies (X2.1 - X2.4) yang memiliki korelasi konstruk dengan indikatorindikatornya lebih tinggi dibandingkan dengan konstruk lainnya (Business Related Competencies, Operational Focus, and Strategic Focus). Sedangkan Operational Focus (Y1.1 dan Y1.2) juga memiliki korelasi konstruk dengan indikatorindikatornya lebih tinggi daripada konstruk lainnya (Business Related Competencies, HR Professional Competencies, Strategic Focus). Strategic Focus (Y2.1 dan Y2.2) memiliki korelasi konstruk dengan indikator-indikatornya lebih tinggi daripada konstruk lainnya (Business Related Competencies, HR professional Competencies, Operational Focus).

Tabel 2. Cross Loading of Discriminat Validity

\begin{tabular}{|c|c|c|c|c|}
\hline Items & $\begin{array}{c}\text { Business Related } \\
\text { Competencies }\end{array}$ & $\begin{array}{c}\text { HR Professional } \\
\text { Competencies }\end{array}$ & $\begin{array}{c}\text { Operational } \\
\text { Focus }\end{array}$ & $\begin{array}{c}\text { Strategic } \\
\text { Focus }\end{array}$ \\
\hline X1.1 & $\mathbf{0 . 9 4 1 4 3 6}$ & 0.593111 & 0.538777 & 0.674895 \\
\hline X1.2 & $\mathbf{0 . 9 4 1 3 3 2}$ & 0.654523 & 0.563082 & 0.653774 \\
\hline X2.1 & 0.671696 & $\mathbf{0 . 9 0 9 2 5 8}$ & 0.806076 & 0.590291 \\
\hline X2.2 & 0.347343 & $\mathbf{0 . 7 9 9 5 6 5}$ & 0.521696 & 0.376403 \\
\hline X2.3 & 0.627126 & $\mathbf{0 . 8 9 7 7 7 6}$ & 0.685468 & 0.527338 \\
\hline X2.4 & 0.590084 & $\mathbf{0 . 8 5 4 2 7 2}$ & 0.525402 & 0.683027 \\
\hline Y1.1 & 0.643886 & 0.574103 & 0.398516 & $\mathbf{0 . 9 1 0 7 7 2}$ \\
\hline Y1.2 & 0.642699 & 0.589953 & 0.469581 & $\mathbf{0 . 9 1 2 3 3 7}$ \\
\hline Y2.1 & 0.487164 & 0.652635 & $\mathbf{0 . 9 3 6 1 4 7}$ & 0.405914 \\
\hline Y2.2 & 0.610036 & 0.749606 & $\mathbf{0 . 9 5 3 3 8 1}$ & 0.488447 \\
\hline
\end{tabular}

Sumber : Data primer diolah, Suryaningtyas, 2011: 92

Metode lain untuk mengukur discriminant validity adalah menggunakan AVE (Average Varians Extracted) untuk setiap konstruk. Skor AVE tiap variabel harus lebih dari 0.50 , sehingga tiap variabel yang digunakan adalah valid. Output PLS pengukuran AVE disajikan dalam Tabel 3, yang menunjukkan AVE untuk seluruh variabel lebih dari 0.50 , maka variabel-variabel yang digunakan didalam penelitian ini adalah valid.

Table 3. AVE

\begin{tabular}{|l|c|c|c|}
\hline \multicolumn{1}{|c|}{ VARIABLES } & AVE & AVE Standard & MARK \\
\hline Business Related Competencies & 0.886204 & 0.50 & Valid \\
\hline HR Professional Competencies & 0.750459 & 0.50 & Valid \\
\hline Operational Focus & 0.892653 & 0.50 & Valid \\
\hline
\end{tabular}


184 MODERNISASI, Volume 9, Nomor 3, Oktober 2013

\begin{tabular}{|l|c|c|c|}
\hline Strategic Focus & 0.830932 & 0.50 & Valid \\
\hline
\end{tabular}

Sumber : Data primer diolah, Suryaningtyas, 2011: 93

\section{b. Composite Reliability}

Indikator blok yang mengukur konstruk dapat dievaluasi dengan dua macam pengukuran, seperti internal concistency yang dikembangkan oleh Werts, Linn \& Joreskog (1974) dan Cronbach's Alpha. Critical score yang dapat diterima untuk level composite reliability ( $\rho c$ ) lebih dari 0.70 (Ghozali, 2008: 25). Dengan menggunakan output PLS, Tabel 4 disajikan hasil tes Composite Reliability dan Cronbach's Alpha adalah lebih dari 0.70. Hal ini menunjukkan bahwa seluruh variabel yang digunakan dalam penelitian ini memiliki reliabilitas yang baik.

Tabel 4. Composite Reliability dan Cronbach's Alpha

\begin{tabular}{|l|c|c|c|c|}
\hline \multicolumn{1}{|c|}{ VARIABLES } & $\begin{array}{c}\text { Composite } \\
\text { Reliability }\end{array}$ & $\begin{array}{c}\text { Cronbach's } \\
\text { Alpha }\end{array}$ & $\begin{array}{c}\text { CR \& CA } \\
\text { Standard }\end{array}$ & MARK \\
\hline Business Related Competencies & 0.939669 & 0.871592 & 0.70 & Reliable \\
\hline HR Professional Competencies & 0.923075 & 0.889503 & 0.70 & Reliable \\
\hline Operational Focus & 0.943278 & 0.880429 & 0.70 & Reliable \\
\hline Strategic Focus & 0.907660 & 0.796535 & 0.70 & Reliable \\
\hline
\end{tabular}

Sumber : Data primer diolah, Suryaningtyas, 2011: 94

Inner Model (Structural Model)

Pengetesan untuk model struktural dilakukan dengan penilaian $R$-Square score untuk konstruk dependen, Stone-Geisser Q-Square test untuk relevansi prediktif, dan $t$ test serta parameter coefficient significancy dari tiap structural linear yang diperoleh dari prosedur bootstrapping untuk pengetesan hipotesis (Ghozali, 2008:26).

Table 5. R - Square

\begin{tabular}{|l|c|}
\hline \multicolumn{1}{|c|}{ VARIABLES } & $\mathrm{R}-$ Square \\
\hline Business Related Competencies & --- \\
\hline HR Professional Competencies & --- \\
\hline Operational Focus & 0.570618 \\
\hline Strategic Focus & 0.550092 \\
\hline
\end{tabular}

Sumber : Data primer diolah, Suryaningtyas, 2011: 95

Berdasarkan output PLS yang disajikan dalam Tabel 5, $R$-Square pada Operational Focus adalah 0.5706. Data ini menunjukkan bahwa model tersebut memiliki Goodness of Fit sebesar 57.06\%. Hal ini berarti bahwa variabilitas X1 (Business Related Competencies) dan X2 (HR Professional Competencies) memberikan kontribusi kepada Operational Focus setara dengan 57.06\%, sementara sisanya sebesar $42.94 \%$ dikontribusikan oleh variabel-variabel lain diluar penelitian ini. Hasil kedua dari R-Square pada Strategic Focus adalah 0.5501. Data ini menunjukkan bahwa model tersebut memiliki Goodness of Fit sebesar 55.01\%. Hal 
ini berarti bahwa variabilitas X1 (Business Related Competencies) dan X2 (HR Professional Competencies) memberikan kontribusi kepada Strategic Focus sebesar $55.01 \%$. Sisanya sebesar $44.99 \%$ dikontribusikan oleh variabel-variabel lain diluar penelitian ini.

$Q$-Square test untuk relevansi prediktif adalah mengukur bagaimana skor observasi bagus dihasilkan dari model dan juga estimasi parameternya. $Q^{2}$ score memiliki range $0<\mathrm{Q}^{2}<1$, dimana skor paling dekat adalah 1 , model lebih baik. $Q$-Square diperoleh dengan menggunakan formula :

$$
\begin{gathered}
\mathrm{Q}^{2}=1-\left(1-\mathrm{R}_{1}^{2}\right)\left(1-\mathrm{R}_{2}^{2}\right) \ldots\left(1-\mathrm{R}_{\mathrm{p}}{ }^{2}\right) \\
\mathrm{Q}^{2}=1-(1-0.5501)(1-0.5706) \\
=1-0.1932=0.8068
\end{gathered}
$$

$Q^{2}$-Square score yang dihasilkan adalah 0.8068 , mengarah kepada skor observasi yang dihasilkan oleh model dan juga estimasi parameter telah mengukur $80.68 \%$ lebih baik.

Pengujian Hipotesis

Pengujian hipotesis dilakukan dengan menggunakan metode Bootstrap resampling, dikembangkan oleh Geisser \& Stone. Pengetesan statistik yang digunakan adalah $t$ test. Aplikasi metode resampling agar distribution free memberikan efek, tidak membutuhkan asumsi distribusi normal dan tidak membutuhkan jumlah sampel yang besar (minimal sampel adalah 30). Signifikansi statistik ada pada p-value $\leq 0,05$ (alpha 5\% = 1.96) (Ghozali, 2008: 44). Berdasarkan Tabel 6, output PLS menghasilkan data sebagai berikut:

a. Business Related Competencies memiliki pengaruh positif terhadap Strategic Focus dengan path coefficient sebesar 0.5038, dan $t$ values diperoleh sebesar 3.276, lebih tinggi dibandingkan $t$ table sebesar 2.015, sehingga H0 ditolak. Hasil ini berarti Business Related Competencies memiliki pengaruh yang signifikan terhadap HR Roles pada Strategic Focus.

Tabel 6. Bootstrapping Result : Path Coefficient

\begin{tabular}{|c|c|c|c|c|c|}
\hline Relationship of Variables & $\begin{array}{c}\text { Original } \\
\text { Sample (O) }\end{array}$ & $\begin{array}{c}\text { Sample } \\
\text { Mean (M) }\end{array}$ & $\begin{array}{c}\text { Standard } \\
\text { Deviation } \\
\text { (STDEV) }\end{array}$ & $\begin{array}{c}\text { Standard } \\
\text { Error } \\
\text { (STERR) }\end{array}$ & $\begin{array}{c}\text { T Statistics } \\
(\mid \text { O/STERR|) }\end{array}$ \\
\hline $\begin{array}{c}\text { Business Related } \\
\text { Competencies -> Operational } \\
\text { Focus }\end{array}$ & 0.162631 & 0.156494 & 0.079782 & 0.079782 & 2.038446 \\
\hline $\begin{array}{c}\text { Business Related } \\
\text { Competencies -> Strategic } \\
\text { Focus }\end{array}$ & 0.503801 & 0.499670 & 0.153765 & 0.153765 & 3.276432 \\
\hline $\begin{array}{c}\text { HR Professional } \\
\text { Competencies -> Operational } \\
\text { Focus }\end{array}$ & 0.637741 & 0.655656 & 0.068255 & 0.068255 & 9.343509 \\
\hline $\begin{array}{c}\text { HR Professional } \\
\text { Competencies -> Strategic } \\
\text { Focus }\end{array}$ & 0.304694 & 0.307555 & 0.145947 & 0.145947 & 2.087701 \\
\hline
\end{tabular}

Sumber : Data primer diolah, Suryaningtyas, 2011: 96 
186 MODERNISASI, Volume 9, Nomor 3, Oktober 2013

b. HR Professional Competencies memiliki pengaruh yang positif terhadap Operational Focus dengan path coefficient sebesar 0.6377, dan $t$ values diperoleh sebesar 9.343, lebih tinggi dibandingkan dengan $t$ table sebesar 2.015, sehingga H0 ditolak. Hasil ini berarti HR Professional Competencies memiliki pengaruh yang signnifikan terhadap HR Roles pada Operational Focus.

c. Business Related Competencies memiliki pengaruh yang positif terhadap Operational Focus dengan path coefficient sebesar 0.1626, dan $t$ values diperoleh sebesar 2.038, lebih tinggi dibandingkan dengan $t$ table sebesar 2.015, sehingga H0 ditolak. Hasil ini berarti Business Related Competencies memiliki pengaruh yang signifikan terhadap $H R$ Roles pada Operational Focus.

d. HR Professional Competencies memiliki pengaruh yang positif terhadap Strategic Focus dengan path coefficient sebesar 0.3047, dan $t$ values sebesar 2.088, lebih tinggi dibandingkan dengan $t$ table sebesar 2.015, sehingga H0 ditolak. Hasil ini berarti HR Professional Competencies memiliki pengaruh yang signifikan terhadap HR Roles pada Strategic Focus.

\section{PEMBAHASAN}

Kerangka kerja penelitian yang digunakan sebagai structural model dalam analisis Partial Least Square (PLS) telah dilakukan pengetesan Goodness of Fit dengan penilaian $R$-Square. Hasil tertinggi dari $R$-Square adalah pada Operational Focus, yang memiliki skor sebesar 0.5706. Hasil ini menunjukkan bahwa model tersebut memiliki Goodness of Fit sebesar 57.06\%. Jika skor ini dibandingkan dengan skor $R$-Square pada Strategic Focus, yaitu sebesar 0.5501, variabilitas dari Business Related Competencies (X1) dan HR Professional Competencies (X2) lebih tepat kepada Operational Focus (Y2).

Didalam pengetesan hipotesis, masing-masing hipotesis dibuktikan dengan menggunakan hasil dari output PLS yaitu Bootstrapping. Pada Tabel 6 disajikan data hasil pengetesan tersebut. Hasil pengetesan Business Related Competencies memiliki pengaruh positif terhadap HR Roles pada Strategic Focus dengan path coefficient sebesar 0.5038 dan signifikan pada $t$ values sebesar 3.276. HR Professional Competencies memiliki pengaruh positif terhadap HR Roles pada Operational Focus dengan path coefficient sebesar 0.6377 dan signifikan pada $t$ values sebesar 9.343. Sedangkan Business Related Competencies memiliki pengaruh yang positif terhadp HR Roles pada Operational Focus dengan path coefficient sebesar 0.1626 dan signifikan pada $t$ values sebesar 2.038. Dan hasil terakhir, HR Professional Competencies memiliki pengaruh positif terhadap $H R$ Roles pada Strategic Focus dengan path coefficient sebesar 0.3047 dan signifikan pada $t$ values sebesar 2.088. Seluruh path coefficients bersama-sama dengan $t$ values memberikan hasil lebih tinggi dibandingkan dengan $t$ tables sebesar 2.015. Hasil tersebut menunjukkan bahwa seluruh hipotesis terbukti memiliki pengaruh yang signifikan. Berdasarkan skor path coefficient dan skor $t$ values dari masingmasing hipotesis yang telah disebutkan diatas, dapat diketahui bahwa pengaruh yang paling signifikan adalah HR Professional Competencies terhadap HR Roles pada Operational Focus sebesar 0.6377 dengan $t$ values sebesar 9.343. 
Dari data hasil pengetesan dapat diketahui bahwa pengaruh paling signifikan adalah pada HR Professional Competencies terhadap HR Roles pada Operational Focus sebesar 0.6377 dengan $t$ values sebesar 9.343. Dengan demikian dapat dikatakan bahwa sebagian besar profesional SDM atau Manajer SDM yang bergabung di dalam komunitas para Manajer SDM di Sidoarjo dan Pasuruan memiliki kompetensi pda dimensi HR Professional Competencies yang terdiri dari kompetensi-kompetensi Credible Activist, Operational Executor, Talent Manager \& Organizational Designer, dan Culture \& Change Steward. Kompetensi-kompetensi ini digunakan didalam mengimpelementasikan peranperan Operational Focus yaitu peran-peran profesional SDM sebagai Employee Champion dan Administrative Expert. Keseluruhan kompetensi tersebut diatas secara komprehensif diwujudkan kedalam peran-peran Employee Champion dan Administrative Expert secara terintegrasi pula.

\section{KESIMPULAN}

Berdasarkan hasil analisis data dan pembahasan, maka dapat disimpulkan bahwa responden yaitu para profesional SDM yang tergabung didalam komunitas Manager SDM di Sidoarjo dan Pasuruan masih menjalankan peran-peran SDM yang tradisional dan belum menjalankan transformasi sumber daya manusia. Responden masih menjalankan aktifitas SDM yang fokus pada pekerjaan seharihari dan saat ini yang bersifat operasional dan berorientasi pada orang. Kompetensi para profesional SDM tersebut masih berada didalam kompetensi pada level menjalankan peran-peran SDM operasional. Peran-peran SDM yang dijalankan responden tersebut masih belum mendukung pada pencapaian tujuan strategis organisasi yang memiliki keunggulan dalam bersaing. Jika organisasi ingin melakukan transformasi sumber daya manusia, maka dibutuhkan bantuan pihak ketiga dalam hal ini konsultan manajemen. Dan didukung pula oleh responden tersebut harus melakukan transformasi terhadap diri mereka sendiri untuk memiliki kompetensi-kompetensi yang dibutuhkan untuk menjalankan peran-peran SDM yang strategis.

\section{DAFTAR PUSTAKA}

Bhatnagar, J. \& Sharma, A. (2005), The Indian Perspective of Strategic HR Roles and Organizational Learning Capability, International Journal of Human Resource Management. 16:9 September 2005 1711-1739, Retrieved September 4, 2010.

Boselie, J. Paul and Paauwe, J. (2005) Human Resource Function Competencies in European Companies, Visiting Fellow Working Paper, Paper 11. Cornell University ILR School DigitalCommons@ILR. http://digitalcommons.ilr.cornell.edu/intlvf/11. Retrieved Sept 4, 2010.

Creswell, John.W. (1994), Research Design: Qualitative and Quantitative Approaches, SAGE Publications, Inc. 2455 Teller Road, Thousand Oaks, California 91320. 
Crouse, P., Doyle, W., Young, J.D., (2011), Trends, Roles, and Competencies in Human Resource Management Practice: A perspective from practitioners in Halifax, Canada, Proceeding of ASBBS, ASBBS Annual Conference, Las Vegas.

Erasmus, B., Loedolff V. Pieter, Hammann, F. (2010), Competencies For Human Resource Development Practitioners, 2010 EABR \& ETLC Conference Proceedings Dublin, Ireland.

Gomez-Mejia, L, et al. (2001), Managing Human Resources, International Edition, 3rd Edition, Prentice Hall.

Grossman, R.J (2007), New competencies for HR, HR Magazine, Vol. 52 No. 6, June 2007, Retrieved October 11, 2010.

Ghozali, Imam (2008), Structural Equation Modelling: Metode Alternatif dengan Partial Least Square, second edition, Badan Penerbit Undip, Semarang.

Hinkle, D.E, et al (1988), Applied Statistics for the Behavioral Sciences, Houghton Miffin Company, One Beacon Street, Boston, MA 02108, USA.

Inyang, B. James (2010), Strategic Human Resource Management (SHRM): A Paradigm shift for achieving sustained competitive advantage in organization, International Bulletin of Business Administration, ISSN: 1451-243X Issue 7, 2010, @EuroJournal, Inc. 2010, http://Eurojournal.com.

Lachance, Janice R., (1999), Looking to the Future: Human Resource Competencies, An Occupation in Transition, A Comprehensive Study of the Federal Human Resources Community, United States Office of Personnel Management.

Lemmergaard, J. (2008), From Administrative Expert to Strategic Partner, Employee Relations Vol. 31 No. 2, 2008 pp. 182-196 q Emerald Group Publishing Limited 0142-5455 DOI 10.1108/01425450910925328.

Long, Choi S. \& Wan, K.W. Ismail (2008), Understanding the Relationship of HR Competencies \& Roles of Malaysian Human Resources Professionals. European Journal of Social Sciences - Volume 7, Number 1 2008, Retrieved June 30, 2010.

Long, Choi S. (2008), Examining Human Resource Competencies and Their Relationships to the Success Factors of HR Profession, J. Serv.Sci.and Management, 1: 259-265 - Published Online December 2008 in Sci.Res (www.SciRP.org/journal/jssm), Retrieved October 11, 2010.

Long, Yu (2009), The Impact of Information Technology on the HR Function Transformation, Master Thesis, Business Administration HRM, University of Twente, March 2009, Retrieved May 12, 2011.

Malhotra, Naresh K. (1999). Marketing Research: An Applied Orientation, 3rd Edition, Prentice-Hall, Inc. Upper Saddle River, New Jersey 07458.

Malhotra, Naresh K. (2006), Riset Pemasaran : Pendekatan Terapan, Georgia Institute of Technology, PT Indeks Kelompok Gramedia, Jakarta.

Malhotra, Naresh K. (2009), Basic Marketing Research: A Decision - Making Approach, third edition, Prentice-Hall, Pearson Education Inc. Upper Saddle River, New Jersey 07458. 
McEvoy, Glenn M. et al (2005), A Competency-Based Model For Developing Human Resource Professionals, Utah State University, Journal Of Management Education / June 2005.

Mondy, R. Wayne (2010), Human Resource Management, Eleventh Edition, Pearson Education Inc., publishing as Prentice Hall, One Lake Street, Upper Saddle River, New Jersey, 07458.

Nurhayati, Siti F. (2001). Analisis Implementasi Peran Sumber Daya Manusia Sebagai Mitra Strategik, Ahli Administratif, Employee Champion, dan Agen Perubahan: Studi pada Top Companies di Indonesia, ISSN 0853 7665, JSB No. 6 Vol. 1 Tahun 2001, Retrieved September 4, 2010.

Payne, M. Liisa (2010), A Comparative Study of HR Managers' Competencies in Strategic Roles, International Management Review, Vol. 6 No. 2, 2010.

Ramlall, S.J. (2006), Identifying and Understanding HR Competencies and Their Relationship to Organizational Practices. Applied HRM Research, Vol. 11 (1), pp. 27-38, Retrieved October 14, 2010.

Sharpe, Ricki (2007), Key Competencies for Human Resources, Article, Retrieved October 11, 2010.

Shermon, Ganesh (2004), Competency based HRM,Tata McGraw Hill, Education Private Limited, 7 West Patel Nagar, New Delhi 110 008, Eighth reprint 2010.

Soetjipto, Budi W., Dr., Penyunting, (2008), HR Excellence 2007, Kisah Sukses Para Kampiun SDM, Lembaga Management Fakultas Ekonomi Universitas Indonesia \& Majalah SWA, Penerbit Salemba Empat, Jakarta.

Sugiyono, (2004), Metode Penelitian Bisnis, 5th Printed, Alfabeta, Bandung.

Suryaningtyas, Dianawati, (2011), The Roles and Competencies of Human Resource Professionals within Human Resource Transformation in Sidoarjo and Pasuruan Manufacturing Industries, Thesis

Tjahjono, H. Kurnianto, ( ), Peran-peran Sumber Daya Manusia: Telaah Konsepsual dan Validasi Empiris, Faculty of Economic, Muhammadiyah University, Yogyakarta, Retrieved September 15, 2010.

The RBL Group (2010). HR Competencies Assessments, Article, Retrieved October 2010.

Ulrich, D. (1997). Human Resource Champions: The Next Agenda for Adding Value and Delivery Results, Harvard Business School Press. Web: http://books.google.co.id/books/id.

Ulrich, D. and RBL Research Team (2010), Research on Asia: The Human Resource Competency Study Singapore. Singapore Human Capital Summit, Report, Retrieved October 11, 2010.

Ulrich, D., Brockbank, W, Johnson D., Younger, J. (2010), Human Resource Competencies: Responding To Increased Expectations, Article, Retrieved October 11, 2010.

Ulrich, D., Allen, J, Brockbank, W, Younger J, Nyman, B. (2009), HR Transformation: Building Human Resources from the Outside In, The RBL Institute, McGraw-Hill Books, USA.

Umar, Husein, (2001), Metodologi Penelitian: Aplikasi dalam Pemasaran, Penerbit PT Gramedia Pustaka Utama, Jakarta. 
190 MODERNISASI, Volume 9, Nomor 3, Oktober 2013

Wang, D. Yau \& Niu, H. Jen (2010), Multiple Roles of Human Resource Department in Building Organizational Competitiveness - Perspective of Role Theory, International Management Review, Vol. 6 No. 2, 2010.

Yeung, A., Woolcock, P, Sullivan, J. (1996), Idenfiying and Developing Human Resource Competencies for the Future: Keys to Sustaining the Transformation of HR Functions, The California Strategic Human Resource Partnership Human Resource Planning, Volume 19, Number 4, Pages 48-58.

Yusoff, Y.M. and Abdullah, H.S. (2008), HR Roles and Empowering the line in Human Resource Activities: a Review and Proposed Model, International Journal of Business and Society, Volume 9 No. 2, 2008, 9-19. 